種々の雰囲気での $(\mathrm{Ca}, \mathrm{Sr}) \mathrm{CuO}_{2}$ の合成と元素置換

\author{
小川 稔, 武田 保雄 \\ 今西誠之, 山本 治 \\ 三重大学工学部, 7514 进市上邱町.

\section{Preparation of $(\mathrm{Ca}, \mathrm{Sr}) \mathrm{CuO}_{2}$ under Various Oxygen Partial Pressure and Substitution of Elements} \\ Minoru Ogawa, Yasuo Takeda \\ Nobuyuki Imanishi and Osamu Yamamoto \\ Faculty of Engineering, Mie University, Tsu 514.
}

Received July, 51993

The solid solution region of infinite-layered copper oxide $\mathrm{Ca}_{1-\mathrm{x}} \mathrm{Sr}_{\mathrm{x}} \mathrm{CuO}_{2}$ was studied under various oxygen partial pressure. The stability region expanded with decreasing oxygen pressure. The trials for electron or hole doping were tried, the intercalation of $\mathrm{Li}$ ion by the discharge in $\mathrm{Li}$-battery was possible forming $\left(\mathrm{Ca}_{0.85} \mathrm{Sr}_{0.15}\right)_{0.9} \mathrm{Li}_{\mathrm{x}} \mathrm{CuO}_{2}(\mathrm{x} \approx 0.2)$. Both $a$ and $c$ axes increased with increasing $x$, indicating the reduction of oxidation state of $\mathrm{Cu}$, but it did not bring about superconductivity.

\section{1 はしめに}

$\mathrm{A}_{2} \mathrm{~B}_{2} \mathrm{Ca}_{\mathrm{n}-1} \mathrm{Cu}_{\mathrm{n}} \mathrm{O}_{4+2 \mathrm{n}}(\mathrm{A}=\mathrm{Bi}, \mathrm{Tl} ; \mathrm{B}=\mathrm{Sr}, \mathrm{Ba})$ 系超伝導酸 化物の結晶棈造の母構造となる $\mathrm{n} \rightarrow \infty の(\mathrm{Ca}, \mathrm{Sr}) \mathrm{Cu}_{2}$ は 2 次元 $\mathrm{CuO}_{2}$ 格子の間にアルカリ土類金属が㨉入されて いる簡単な構造で無限層棈造と呼ばれる，無限層構造

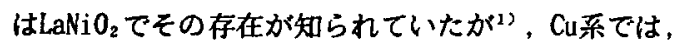
T. Siegristらによってはじめて報告されたもので, 試

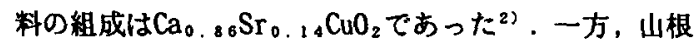
らはこれとは别にこの構造をとるCa $0 .{ }_{01} \mathrm{Sr}_{0.00} \mathrm{CuO}_{2}$ を 報告した ${ }^{3)}$. いずれにしても大気圧下ではCa: $\mathrm{Sr}=$ 0.9:0.1 付近のこく狭い組成範囲でのみ安定な構造であ ろ.最近，高野らは高圧合成法によってホールドープ 系の無限層超伝導体の合成に成功し4.5)，また同様の 方法でCoodenoughら"2) 金丸ら"によって電子ドープ 系の無限層超伝導体 $\mathrm{Sr}_{1-\mathrm{x}} \mathrm{R}_{\mathrm{x}} \mathrm{CuO}_{2}$ ( $\mathrm{R}$ :希土類) が合成さ れた. 高圧合成では広い籍囲のアルカリ土類の組合せ
が可能であった．高圧合成法の他に河合，川合らのレ 一ザーM B E による薄膜の無限層構造の合成も行われ ている.この場合も広い組成籍囲の合成が可能で，一 部超伝導になるという報告もある.大気压下で得られ る無限層化合物は絶縁体に近い抵抗率を示し超伝導に は至らない，この大気圧下で得られる狭い組成篹围の 無限層構造酸化物にキャリアーをドープして超伝導を 出現させようとする試みが多くなされている様だが， いまだ成功した報告はない，我々の目的は，大気压下 で合成される無限層構造中に有効なキャリアーをドー プし超伝導を出現させるための基砧研究として，この 構造の安定領域を検討することである．またそれに合 わせて様々な元素置換によるキャリアーの注入を試み た. とくに一種の電気化学的還元というべきリチウム 電池によるLiイオンの㨂入を行い，ある程度の $\mathrm{Cu}_{2}$ 平 面の塁元に成功した. 


\section{2 実 酸}

$\mathrm{Ca}_{\mathrm{x}} \mathrm{Sr}_{1-\mathrm{x}} \mathrm{CuO}_{2}$ の合成においては出発原料として $\mathrm{CaCO}_{3}, \mathrm{SrCO}_{3}, \mathrm{Cu} 0$ 各粉末を用い， $\mathrm{x}=0.925-0.8$ 試料 を調製した，錯体重合法 $\left.{ }^{8}\right)$ にって高分子ゲルを得た 後，仮姥を絽り返し，最終的には $980^{\circ} \mathrm{C} て ゙ 10$ 時間， $\mathrm{O}_{2}-\mathrm{N}_{2}$ 混合ガス気流中で本焼した.アルカリ土類の一部 をアルカリ金属で贯換した試料の合成は，原料として 炭酸塩に比へてはるかに活性であり低温で反応を促進 すると思われる過酸化物を用いた．過酸化物が水分や 有機溶媒にたいして反応性が高いため上述のような方 法でCu-richな組成で試料をつくり，後にドライボック ス中過酸化物之湿合し焼成した，希土類置換試料の合 成には出発原料としてY $\left(\mathrm{NO}_{3}\right)_{3} \cdot 5 \mathrm{H}_{2} \mathrm{O}$ ，または $\mathrm{Nd}_{2} \mathrm{O}_{3}$ を用 い，錯体重合法によって試料を調慗し，各酸素分圧下， $980^{\circ} \mathrm{C} ， 10$ 時間で処理した．また，以下に示す 2 極式コ インタイプセルを用いた電気化学的リチウム㨉入によ る遇元も行なった。

\section{$\mathrm{Li} / 1 \mathrm{H}-\mathrm{LiClO}_{4}$ in $\mathrm{PC}+\mathrm{DME} /$ Sample}

試料は枌末 X線回折法により同定し，酸素量はヨー ドメトリーにより決定した。抵抗率は通常の 4 端子法 により室温から15Kまで測定した。

\section{3 却果と考察}

$\mathrm{O}_{2}-\mathrm{N}_{2}$ 混合ガス気流中の酸素分圧を変化させて， $\mathrm{Ca}_{x} \mathrm{Sr}_{1-x} \mathrm{CuO}_{2}(0.925<\mathrm{x}<0.8)$ の焼成を行なった、試み た酸素分圧下では温度が $980^{\circ} \mathrm{Cに}$ 近い領域でのみ無限層 構造が出現した．焼成時の雾团気を 1 気圧酸柔とする と， $x=0.9$ 付近のこく狭い組成籍囲でのみ単一相の無限 層化合物が得られたが，酸素分圧を適度に低下させる ことでより広い組成籍囲で単一相の合成が可能となっ た. Fig. $1 に 50 \% 0_{2}$ 乙25\% $0_{2}$ 雾囲気で焼成した場合のX RDパターンを示す. 明らかに低い酸素分圧 $\left(25 \% 0_{2}\right)$ の 方が固溶域が広がっているのが分かる．不純物相とし

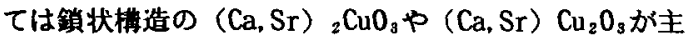
であった。この固溶篹囲における格子定数は，Caをよ クイオン半经の大きなSrで置換するにつれ直線的に增 加した．その様子を 3 種の $0_{2}$ 雾囲気における $\mathrm{x}$ に対す る a ，c 軸変化としてFig. 2に示す. 酸素分圧20\%では $\mathrm{x}=0.825-0.9$ の管囲で固溶体が生成されるが，これより 低い酸素分圧では試料が焼成温度で融解した. Fig. 3は 比䡈的容易に幅広い酸素分圧下で単一相の得られた 2 種の試料（ $x=0.875 ， 0.9 ）$ につて格子定数とヨード メトリーによって決定した酸素量の関係を示している。 酸素量は何れの試料の場合もほほ 2 であるが, 合成時 の酸素分压が下がるにつれて嚾かながら減少しており， 酸素分圧の低いところでは $\mathrm{c}$ 軸長と対称的な変化を示 した. 酸素分圧の高いところで比較的大きな酸素量を 示しているのは，僅かに含まれる不純物相のためであ
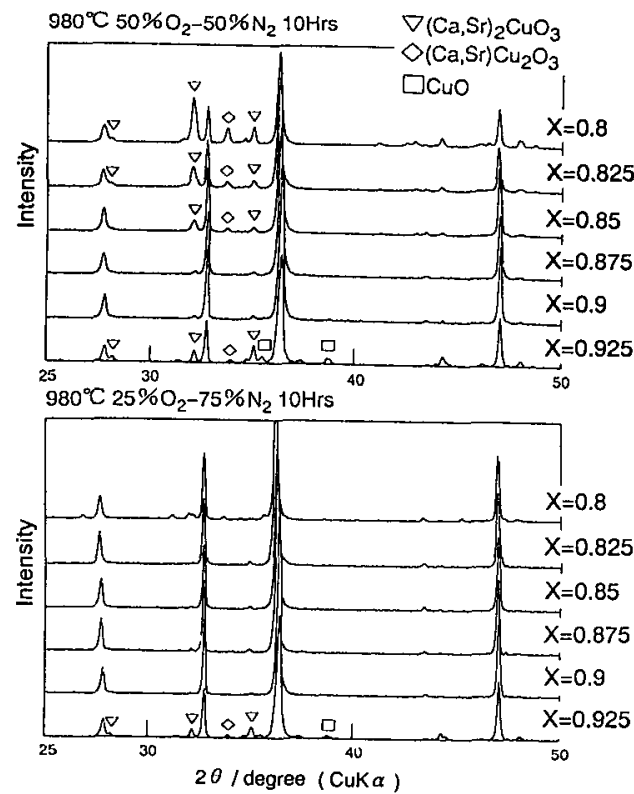

Fig.1 XRD patterns for $\mathrm{Ca}_{x} \mathrm{Sr}_{1-x} \mathrm{CuO}_{2}$.
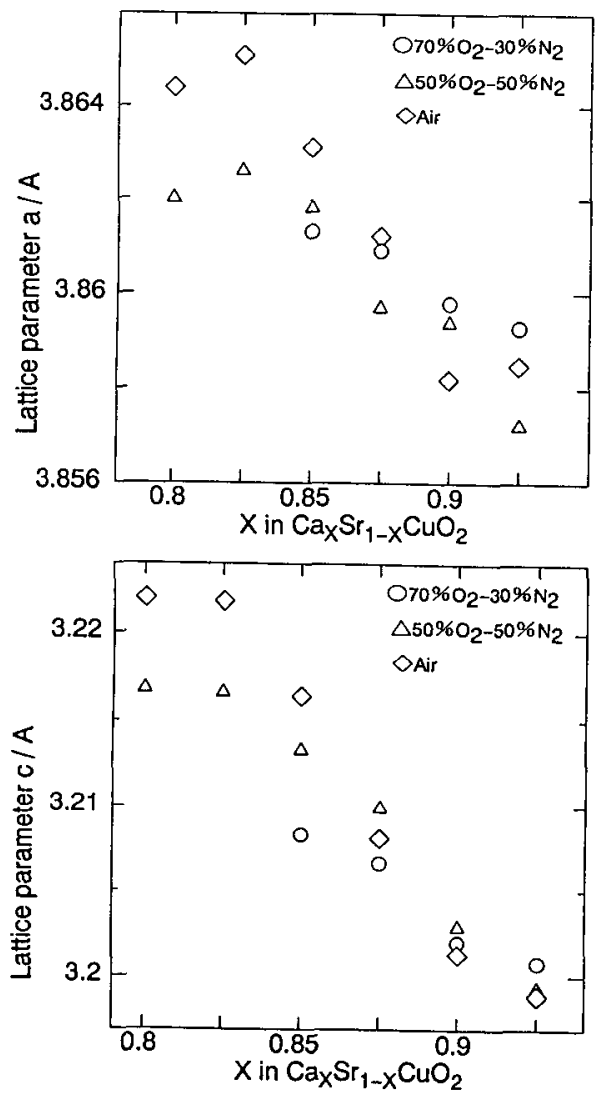

Fig. 2 Variation of lattice parameters for $\mathrm{Ca}_{\mathrm{x}} \mathrm{Sr}_{1-\mathrm{x}} \mathrm{CuO}_{2}$ prepared under various oxygen partial pressure. 

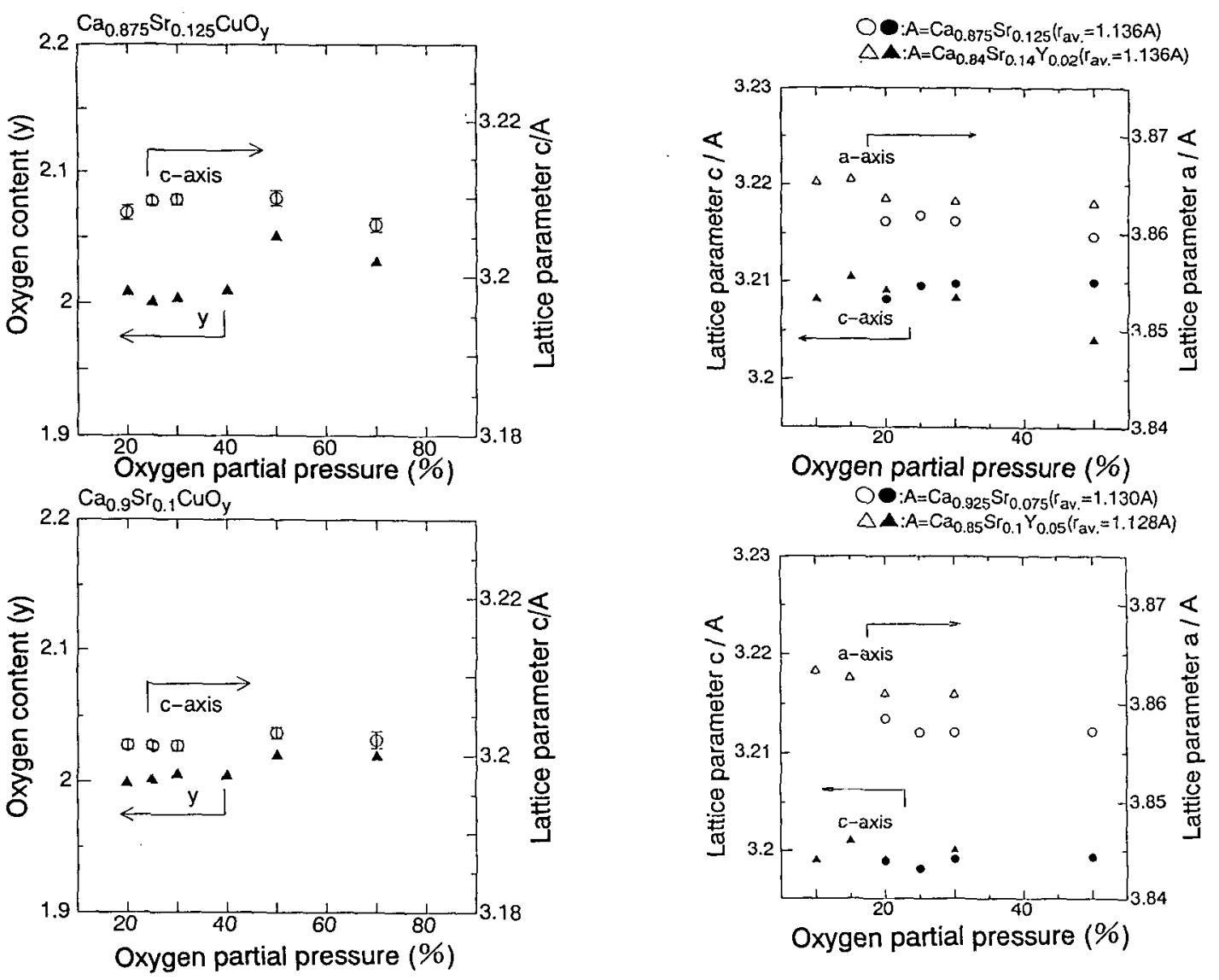

Fig.3 Variations of lattice parameters and oxygen content for $\mathrm{Ca}_{x} \mathrm{Sr}_{1-x} \mathrm{CuO}_{y}$ on partial oxygen pressure.

ると思われる．無限層構造の出現領域は平均イオンサ イスに加えて合成時の酸素分圧がかりの影製を及ほ していることが分かった。

アルカリ土類金属をアルカリ金属あるいは希土類元 素での置換においては、いずれの場合も無限首構造が 不安定化する力向一反応が進み多量の置換は不可能で あった.アルカリ金属置換の場合，過酸化物の利用に よって低温度の反応の促進を期待したが，実際には無 限層搆造の分解が起こり，単一相として得ることが不 可能であった，希土類置換の場合，非置换系に比へて より低い酸素分压下で反応が促進された，極めて微量 の置换ではあったが単一相として得られたイットリウ 么置換系についての格子定数率化をFig. 4に示す. $10 \%$ $\mathrm{O}_{2}$ で焼成した試料の格子定数は $\mathrm{a} ， \mathrm{c}$ 軸亡もに東北大 のグループが報告した值と良く一致している゙，比較 のために平均イオンサイズの等しいものを重わておい たが，いずれの酸素分圧下においても特に $\mathrm{a}$ 軪長の增 如する㑯向がみられた。このことはイットリウムドー

プによって無限首構造中にエレクトロンが注入された ことを示唆する結果であった．先のグループが $\mathrm{Ca}_{0.82} \mathrm{Sr}_{0.18} \mathrm{Y}_{0.02} \mathrm{CuO}_{2}$ の組成で抵抗率の異常を報告し たが，我々が行なったFig.4に示した様な組成では同様 の現象は見られなかった，置換前の試料は緦縁体的で あるのに対し，置換後の試料はいずれも半導体的挙動 を示した．しかし超伝導には至らなかった。

Cu-0平面の罯元の一つの方法として電気化学的リチ ウムドープを行なった. $\mathrm{Ca}_{0 .}{ }_{85} \mathrm{Sr}_{0.15} \mathrm{CuO}_{2}$ または $\left(\mathrm{Ca}_{0.85} \mathrm{Sr}_{0.15}\right)_{0.8} \mathrm{CuO}_{2}$ にリチウム電池を組んでリチ ウムを挿入した．リチウムのドープ量を $\mathrm{x}$ とすると， x がかなりの量まで単一相であったＦｉg.5に $\left(\mathrm{Ca}_{0.85} \mathrm{Sr}_{0.15}\right)_{0.8} \mathrm{CuO}_{2}$ の放電による電㮹電圧変化を 示す、また，Fig.6に各放電量で電流をとめたリチウム 㨂入にともなう格子定数変化を示す．あきらかに格子 定数は $\mathrm{x}=0.2$ 付近まで $a ， c$ 軸共に呻びており，それ以 後の伸びは $\mathrm{x}=0.8$ までみられなかった．放電曲線を見る と $\mathrm{x}=0.2$ 付近を境に 2 段階の放電反応であると考えられ 


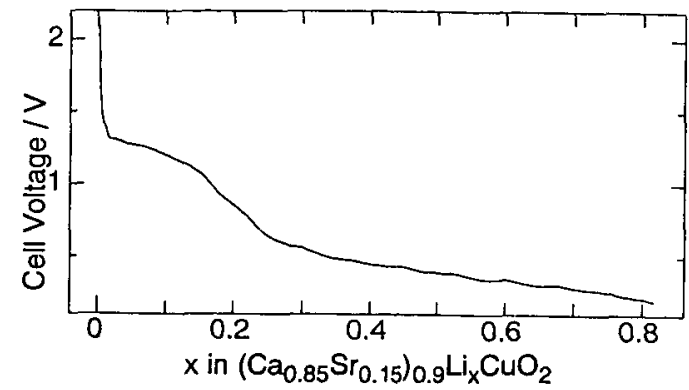

Fig.5 Discharge curve for the battery $\mathrm{Li} /\left(\mathrm{Ca}_{0.85} \mathrm{Sr}_{0.15}\right)_{0.9} \mathrm{CuO}_{2}\left(0.15 \mathrm{~mA} / \mathrm{cm}^{2}\right)$.

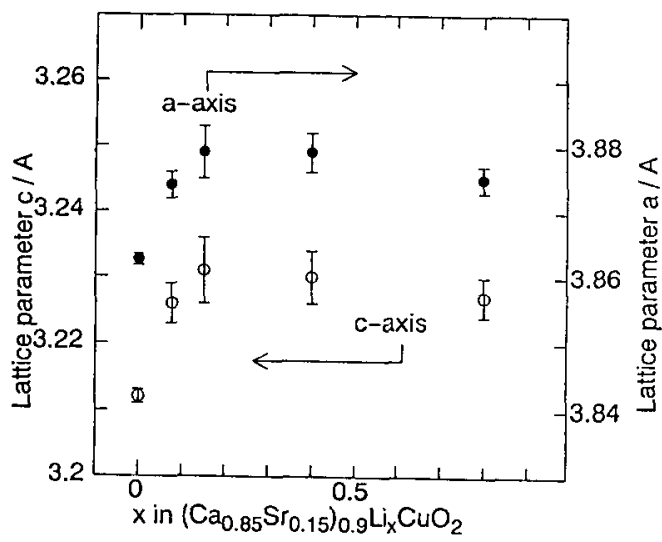

Fig.6 Variation of lattice parameters for $\mathrm{Li}-$ intercalated $\left(\mathrm{Ca}_{0.85} \mathrm{Sr}_{0.15}\right)_{0.9} \mathrm{Li}_{\mathrm{x}} \mathrm{CuO}_{2}$.

る. $X=0-0.2$ までの放電反応では格子定数の伸びから考 えても, リチウムの正確な位置は分かっていないが無 限層檴造へのリチウム捚入反応が実現されていると思 われる. $\mathrm{x}=0.2$ 以降の反応では武料調製の際に道電材と して加えたアセチレンブラックへのリチウム挿人反応 が起こっているのではないかと思われる．リチウムを $\mathrm{x}=0.075-0.8$ まで挿入した試料についてSQUIDによる磁 化率测定を行なった．結果をFig. 7に示す.いずれす超 伝道には至らなかった． $\mathrm{Cu}_{2}$ 平面は十分に塄元されて いるむのの，電子ドープ系超伝導体の出現の際に見ら れるCu-0距離は一般に〜1.97 近くであるので，この

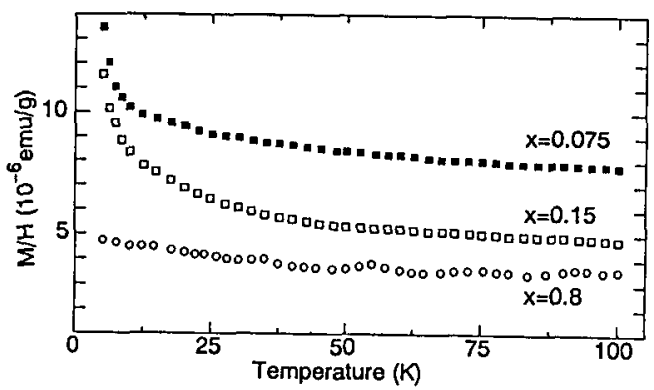

Fig.7 Magnetic susceptibility of $\left(\mathrm{Ca}_{0.85} \mathrm{Sr}_{0.15}\right)_{0.9} \mathrm{Li}_{\mathrm{x}} \mathrm{CuO}_{2}$.

值にわずかに至らないことが原因であるのかも知れな い.

\section{謝 辞}

この研究の費用の一部は文部省重点領域研究「高温 超伝道の科学」の補助金によりました。

\section{文 嘼}

1)P. Levi tz, M. Crespin, and L. Gatineau:J. Chem. Soc. . Faraday Trans. , 79 (1983) 1195.

2)T. Siegrist, S. U. Zahurak, D. T. Hurphy, and R. S. Roth:Nature(London), 334 (1988) 231.

3）山根久典, 宮崎境, 平井敏雄: 日本七ラシクク協会学術論 文誌.97 (1989) 143.

4) H. Takano, Y. Takeda, H. Okada, M. Mi yamoto, K. kusaka: Physica C. 159 (1989) 375.

5)H. Azuma, Z. Hi roi, H. Takano, Y. bando and Y. Takeda: Nature, 356 (1992) 775.

6)H. G. Smi th, A. Manthi ram, J. Zhou, J. B. Goodenough and J. T. Markert: Nature, 351 (1991) 549.

7)G. Er, Y. Miyamoto, F. Kanamaru and S. Kikkawa: Physica C, 181 (1991) 206.

8)M. Kakihana, L. Bör jesson, S. Eriksson and P. Svedlindh: J. App1. Phys. , 69(1991).

9)H. Katsuo, Y. Koike, T. No j i, N. Kobayashi and Y. Sai to:Physica C, 196 (1992) 276. 